\title{
Why is Social Protection Gender- blind? The Politics of Gender and Social Protection
}

\author{
Nicola Jones and Rebecca Holmes
}

\begin{abstract}
Social protection may be high on the policy agenda in international development circles, but the way it plays out in practice at national and local level is deeply political, especially so when viewed through a gender lens. While there is a robust body of evidence on the gendered patterning of poverty and vulnerability, this is seldom reflected in a systematic way in social protection strategies, policies or programmes. This article therefore explores the political economy of social protection and its effects on gender relations to increase understanding about why social protection debates and approaches have been largely gender-blind.
\end{abstract}

\section{Introduction}

Social protection has risen rapidly up the policy agenda in international development circles over the last decade as a key mechanism to address poverty and vulnerability. The fallout from the global recession, with millions more people falling below the poverty line, has further underscored the importance of investing in social protection infrastructure (Bauer and Thant 2010). The way in which these broad international trends play out at the national and local levels, however, is often highly political (Hickey 2007), and this is especially so when one applies a gender lens (Molyneux 2007; Kabeer 2008). While there is a robust body of evidence on the gendered patterning of poverty and vulnerability (e.g. Chant 2010), this knowledge base is seldom reflected in a systematic way in social protection strategy, policy and programme design (Holmes and Jones 2010).

This article explores the political economy of a range of social protection instruments (Table 1) and their effects on gender relations at the individual, intra-household and community levels, in order to better understand why social protection debates and approaches to date have been largely gender-blind. Drawing on empirical evidence from a multi-country study undertaken by the Overseas Development Institute (ODI) and national partners in 2009/10 and funded by the Department for International Development
(DFID) and AusAID, it weaves together findings from key informant interviews, household surveys, focus group discussions and life histories from men, women and children across their lifecycle in Africa, Asia and Latin America. The article begins by outlining the key characteristics of gender-sensitive social protection. It then presents a conceptual framework for thinking about gendered political economy which is in turn applied to our empirical cases. The final section concludes by highlighting some key policy implications of our findings.

\section{Gender-sensitive social protection}

In parallel with the increasing recognition of social protection as an important poverty reduction policy tool, the last decade has also seen a renewed interest in the role that addressing gender inequalities can play in achieving broader economic and social development objectives. Surprisingly, however, there has been a profound disconnect between these two agendas. The importance of harnessing the potential of social protection approaches to reshape gender power relations cannot be ignored. Millions of pounds in international development funding are being invested annually in social protection policy and programme development; millions of men, women and children are already participating in social protection programmes; and, given the high level 
Table 1 Programmes covered in the ODI Gender and Social Protection Effectiveness Study

\begin{tabular}{ll}
\hline Type of social assistance & Programme \\
\hline Cash transfers & - Ghana's LEAP quasi-conditional cash transfer \\
& - Peru's Juntos conditional cash transfer \\
Asset transfers & Bangladesh's Challenging the Frontiers of Poverty Reduction \\
Public works programmes & India's National Rural Employment Guarantee Scheme \\
Subsidies (of food and basic services) & - Vietnam's National Targeted Programme for Poverty Reduction (NTPPR) \\
& - Indonesia's RASKIN rice subsidy programme \\
& Mexico's community child crèche system, Estancias
\end{tabular}

of current policy interest globally, there is potential for millions more poor households to be reached as programmes are scaled-up.

Not only are social protection policies and programmes failing to reach their potential effectiveness because gender relations are either neglected altogether or relegated to a secondary concern, but where social protection initiatives have sought to include gender dimensions, they have generally reinforced traditional gender roles by targeting women in their capacities as mothers only. While in some cases social protection programmes have paid welcome attention to the importance of supporting women's care work responsibilities, in general they have had very limited impact in challenging unequal divisions of labour and power imbalances between men and women. By ignoring the importance of gender equality in programme design and implementation, social protection policymakers not only risk failing to leverage national commitments and laws on gender equality but also risk undermining the potential for economic growth and progressive development outcomes that investing in gender equality and women's empowerment can bring about (Holmes and Jones 2010).

Relatively simple design changes, combined with an investment in more strategic implementation practices, can significantly enhance the potential of social protection to contribute to a transformation of gender relations at the individual, intra-household and community levels. Such changes may include the following (see Holmes and Jones 2010).

- Ensuring that vulnerability assessments used to inform programme design are disaggregated and analysed by sex and age. Programme design changes may include a focus on reducing women's time poverty, finding collective solutions to care work responsibilities and improving girls' nutrition and school enrolment.

- Promoting institutional linkages between social protection and a broader package of social and economic policy objectives in order to support women's practical gender needs and transformative potential to change gender relations among men, women, boys and girls more broadly at the household and community levels. Strong linkages are needed, for example, across health and reproductive health services; social development and rights awareness training; credit access and employment training; school allowances and elderly benefits.

- Maximising the potential of the interface between communities and programme implementers to initiate community dialogue on ways to address gender inequalities such as gender-based violence, early marriage, the costs of child labour and gendered forms of social stigmatisation. At the same time, raising community awareness and capacity of the community can enhance understanding of and demand for gender-related social protection programme provisions.

- Investing in the implementation capacity of staff to ensure that gender-sensitive design is translated through to the delivery of programmes. This would require developing tailored and ongoing capacity building for programme implementers and male and female programme participants alike on gender-related programme objectives.

- Improving coordination between actors, for instance between implementing agencies and 


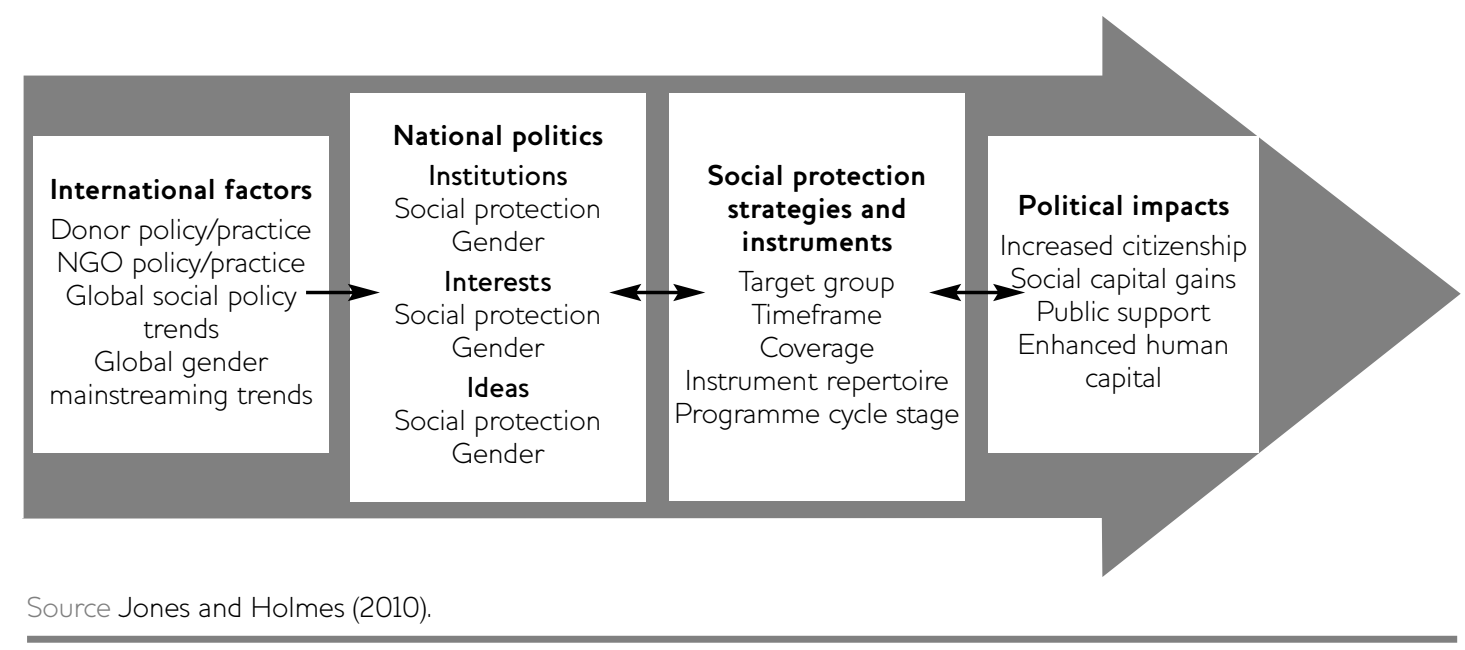

women's government agencies or gender focal points to strengthen their role at the national and sub-national levels in both the design and implementation of social protection.

- Ensuring that monitoring and evaluation is disaggregated and analysed by sex and age so that gender considerations inform programmes. Such indicators could include impacts on girls' health, nutrition and education, women's income, labour market participation, mobility, decision-making power, control over resources and participation in programme governance structures.

- Strengthening women's agency, advocacy and representation, for instance, by promoting women's representation and participation on programme governance committees.

\section{Conceptualising gendered political economy}

Despite the simple steps involved in embedding a gender-sensitive approach in social protection policy and programming, gender mainstreaming in any policy sector is as much a political issue as it is a technical one. Despite this, discussions about social protection in developing countries have tended to focus more on technical, rather than political, issues. This has recently been changing, however, as different levels of elite and public buy-in, social protection programme design choices, and forms of implementation at the grassroots level have become increasingly visible. Analysts have also started to turn their attention to the political economy challenges that the rollout of social protection strategies face (McCord 2009) and have focused on the so-called ' 3 Is' of social protection: (1) Institutions (e.g. elections, political party systems, informal politics such as patron-client relations, monitoring and evaluation systems) and the opportunities or constraints they present for social protection policy and programme development; (2) Interests of key actors (e.g. political elites, bureaucratic agencies, donors and civil society champions) and the relative balance of power between them; and (3) Ideas held by elites and the public regarding poverty and its causes, the social contract between the state and its citizens, and the merits of particular forms of state support.

To date, however, the role of gender in shaping these institutions, interests and ideas has been largely overlooked by mainstream development actors. Accordingly, we employ a modified version of this framework (Figure 1) to assess the challenges involved in integrating a gender perspective into social protection strategy, policy and programme development. We also draw on Hickey's (2007) emphasis on the need to consider politics at three different junctures: the initial decision to embark on a social protection strategy; the choice of particular social protection instruments and programme impacts.

\section{Unpacking institutional motivations for social protection}

Institutional factors play a key role in shaping the divergent parameters of social protection policy choices across country contexts. Across our case studies, these included redressing a legacy of political violence among impoverished communities in the case of Peru's conditional cash transfer programme, Juntos; responding to 
macroeconomic crises in Indonesia's RASKIN rice subsidy programme; harnessing public works labour to promote environmental rehabilitation in Ethiopia's combined public works/social transfer Productive Safety Net Programme (PSNP); and demonstrating a commitment to poverty reduction in the run-up to elections in the case of Ghana's Livelihood Empowerment Against Poverty (LEAP) cash transfer programme. However, only in two cases - Bangladesh's Challenging the Frontiers of Poverty Reduction (CFPR) programme, which aims to promote women's economic empowerment and, in turn, decision-making power within the household, and Mexico's subsidised crèche scheme, Estancias, which aims to increase women's participation in the paid workforce by supporting their care work responsibilities - do tackling gender inequalities feature as primary objectives.

As underscored by a dearth of genderdisaggregated monitoring and evaluation indicators, other initiatives frequently relegate gender-related goals to a secondary status (as is the case with cash transfer programmes that target women so they can play a greater role in supporting their children's human capital development, and with public works programmes that promote women's participation in the schemes but fail to tackle gender discrimination in the allocation of 'appropriate work').

Alternatively, they neglect to tackle the gendered dimensions of poverty and vulnerability altogether. The latter is the case for instance with Vietnam's flagship integrated poverty reduction programme, the National Targeted Programme for Poverty Reduction (NTPPR), which overlooks the language barriers and social discrimination that ethnic minority girls and women in particular may face in accessing human capital and income-generation opportunities. Similarly, in Indonesia, the subsidised food security programme, RASKIN, does not consider the differential nutrition needs within the household. These are of particular concern during different stages of the life cycle, especially for children under five and pregnant and nursing women.

There are a number of explanations for this low prioritisation of gender inequalities. These include an institutional disconnect between the growing body of evidence on the gendered nature of poverty and vulnerability and policy and programme design, in part due to weak linkages between governmental gender focal points and policy and programme designers; and a largely technocratic approach to gender mainstreaming which does not support tailored and operational approaches to the systematic integration of gender. These are in turn exacerbated by an under-investment in capacity building for programme implementers, especially regarding the gendered rationale for programme provisions; and the general absence of gendersensitive indicators in programme monitoring, evaluation and learning systems.

Political economy frameworks also emphasise the important role of informal institutions and the need to pay attention for instance to patterns of patron-client relations. While some programmes in our study were specifically established to correct historical tendencies towards clientelism in the social sector and establish more transparent and accountable modalities of social protection programming (as was the case with the establishment of Juntos in Peru; Vargas 2010), implementation practices often continue to be significantly shaped by informal politics. In Indonesia, targeting has been uneven as village heads have faced and often succumbed to pressures from villagers to provide subsidised rice to a much broader sector of the population. In Vietnam, decisions about how best to invest local infrastructure budgets have on the whole not been approached through a pro-poor lens but have instead been shaped by concerns that all should benefit equally (e.g. through the construction of village meeting buildings). The challenge from a gender perspective in attempting to tackle informal politics is that clientelistic ways of working are typically overlaid with patriarchal ways of relating. Accordingly, without investing in awarenessraising initiatives for programme participants about the gendered rationale for programme provisions, these types of political economy challenges are likely to remain unresolved.

\section{Interests of key actors}

The constellation of actors involved in social protection debates is diverse, including political, social and economic elites who play a key role in setting the terms of the debate. These include administrative bureaucratic agencies with responsibility for delivering social protection objectives (typically spanning a range of ministries: social welfare, women and children's affairs, health, food 
security bureaus and rural development); civil society actors working with or acting on behalf of the poor - both international (e.g. international NGOs such as ActionAid, HelpAge, Save the Children, Oxfam) and national; and bilateral donors (e.g. DFID, GTZ) and multilateral agencies (especially the World Bank and UN agencies such as ILO, UNDP, UNICEF, UNIFEM). While increasingly there are good practice examples of cross-agency cooperation (as evidenced for instance by the initiatives: Advancing Child-Sensitive Social Protection, a joint statement by DFID et al. 2009; and Social Protection in Africa: A Way Forward, a joint statement by CSP et al. 2010), not surprisingly these actors have a range of different interests in promoting social protection, and differing degrees of influence and capacities in particular contexts. A careful mapping of this complex landscape, including a recognition that these different actors are themselves not homogeneous and may have varying interests, is critical for assessing both the opportunities for and potential obstacles to the integration of gender into the social protection agenda.

First, political elites often initiate social protection programmes to further their own institutional aims, such as demonstrating a commitment to a strengthened social contract between the state and the citizenry (as is the case with India's Mahatma Gandhi National Rural Employment Guarantee Act (MGNREGA) which represents a commitment by the state to fulfil the right of all citizens to earn a liveable wage) and promoting social cohesion, especially in times of political flux. The impacts of social protection programmes are also often harnessed by political elites to advance their own interests. In Ethiopia, for instance, the ruling party has been able to shore-up popularity among the rural poor as a result of the highly visible Productive Safety Net Programme (PSNP) (Jones et al. 2010), while Brazil's successful Bolsa Familia programme has helped the PT-led (Workers' Party) government to cement its role as an emerging global power by providing an effective platform from which to lead an initiative on South-South learning. Furthermore, in many cases, even though gender equality concerns are secondary to overall programme aims, governments have often been happy to claim responsibility for progressive gender outcomes. For example, this has been the case with regards to the increased participation of women in Ethiopia and India as a result of public works programmes, the enhanced capacities of female caregivers to support their children's development in Latin American cash transfer programmes, and smoothing women's role in ensuring adequate food consumption in the case of Indonesia's RASKIN programme.

Second, the interests of bureaucratic agencies also influence social protection trajectories to a significant extent, with the lead agency for social protection strategies often playing a key role in shaping the relative priorities accorded to different social protection goals. In areas where ministries of social welfare of women and children lead, there is generally more scope for attention to gender inequalities, although the ability to operationalise this can be limited by the capacity constraints that these agencies typically face in coordinating with other more powerful government agencies (as has been the case to date in Ghana, for example). Where ministries of rural development are the lead agency, gender dynamics tend to be a lower order priority and this is typically exacerbated by the limited integration of a gender perspective into their ways of working, weak linkages to gender focal points and a general dearth of funding for capacity building for programme implementers around these issues (as for instance in Ethiopia, India and Indonesia). How bureaucratic agencies interact with other political players, such as the legislature, may also matter, especially in cases where social protection policies become enshrined in law (as has been the case with India's MGNREGA).

The third key group of actors to consider is civil society. In the African and Asian contexts, international NGOs have played an important role in influencing social protection discourse, although the focus on gender equality has not been as strong as could be expected, in large part because of the primary focus on age-based (Save the Children, HelpAge) and spatial (e.g. Oxfam's work on pastoral communities) exclusion and vulnerability. In Latin America and South Asia, domestic civil society actors have been relatively more influential, especially in Bangladesh, where BRAC has undertaken path-breaking work in social protection programming aimed at supporting women's productive and social capital. However, again, while some gender equality champions (e.g. in Peru, Bangladesh and India) have played a part in ensuring, for instance, equal 
wages for women, sensitivity to women's time poverty, and the importance of forging linkages with complementary programmes that tackle sociocultural forms of gender discrimination, gender equality activists have been much less prominent than in other areas of public debate such as political participation, human and labour rights. This is perhaps because women's movements have not been sufficiently adept at moving away from their more traditional policy strongholds (e.g. women's economic empowerment, gender-based violence, political representation) and strategically influencing new programme areas, such as social protection. Possible reasons include a general tendency for gender equality movements to pay relatively less attention to issues affecting the poorest; the too often narrow income and consumption focus of social protection programmes; and funding pressures which have served to keep women's NGOs siloed rather than facilitating their capacity to engage effectively with cross-sectoral issues such as social protection.

Finally, donors, especially in the sub-Saharan African context, have become critical actors in the social protection field. While the focus has largely been on social protection as a tool to help the poor and vulnerable harness the benefits of economic growth (e.g. DFID, GTZ, ILO, World Bank), UNICEF and UNIFEM have sought to highlight the importance of equity and social inclusion considerations. However, with the exception of UNIFEM, which remains a very small player in the field, gender dynamics have not received much attention to date among donor agencies working on social protection, reflecting a general weakness in gender mainstreaming outside a few key sectors in the donor community. This is gradually changing, especially with regard to exploring the potential of social protection instruments to enhance girls' educational achievement and girls' and women's reproductive health in the context of the broader MDG agenda, but has yet to receive the resourcing a more systematic approach would demand.

\section{Ideas matter}

Political economy analysts emphasise the centrality of ideas (e.g. Hickey and Bracking 2005). This is certainly the case with social protection, where the divergent contours of national social protection systems reflect a wide range of ideas about poverty and its causes, the purpose of social protection and the role of the state in shaping gender relations, as well as the extent to which these ideas are shared by different social groups (see Box 1). In Ethiopia and India, large-scale public works schemes have been informed by public distrust of social protection interventions 'that create dependence' but public backing for the right of all, including female-headed households who are often believed to be especially vulnerable, to have access to work to support their families. Similarly, both Ghana's cash transfer programme (LEAP) and Mexico's subsidised crèche scheme (Estancias) have been framed in terms of harnessing the productive capacities of all citizens, including women, to contribute to broader national economic development goals. Generally, however, support for a more comprehensive approach to tackling gender-specific vulnerabilities has been less forthcoming, as gender relations are often seen as the purview of individual families and/or cultural or religious groups and therefore not an area in which the state should intervene.

\section{Conclusions and policy implications}

Although the links between gender, economic growth and development sustainability have become increasingly well recognised by mainstream development actors, these insights have yet to gain real traction within social protection debates, policy and practice. The key constraints we have highlighted relate to the gendered politics of social protection, and in particular a general tendency for gender dynamics to be integrated into institutions, actor interests and ideas in only a partial and subordinate way. In operationalising the insights from political economy analysis, Sam Hickey (2007: 12) has argued that "[a] key challenge is to identify and support "politically progressive constituencies" or drivers of change, that might begin to provide the forms of mobilisation required to secure political contracts for social protection'. We would add to this that an emphasis on securing political buy-in for gender-sensitive social protection is also essential. In this vein, our multi-country analysis suggests that the following should be considered in developing 'politically progressive constituencies' that are gender-aware.

Assist designers of national social protection strategies to creatively source evidence on the gendered nature of poverty and vulnerability, so that tackling gender inequalities can be 
Sociocultural understandings of citizenship and citizen-state relations often contribute to the challenges in promoting gender-sensitive poverty reduction programming, as the example of Vietnam's NTPPR attests. First, community attitudes towards state-provided poverty reduction efforts are often complex and demand skilful negotiation. For instance, some highland ethnic minority groups have 'a cultural view of the state whereby they are reluctant to participate in activities belonging to the state - whether or not it feeds their needs. The state belongs to the other and so people tend to look within the community first' (Deputy Head, Programme 135, Committee of Ethnic and Minority Affairs 2009). Accordingly, there is a need for programme implementers to build up communities' understanding of the state and of citizenship rights and programme staff need support in developing the appropriate 'soft skills' for such a role.

Language and cultural diversity have not been adequately factored into programme design in many cases. Especially in ethnic minority communities, women in particular are often unaware of programme provisions, owing to language barriers. Language hurdles can also be compounded by cultural gender roles and gendered education and literacy gaps, so that women are less likely to contribute to community discussions (Chair, Vietnamese Women's Union, Lao Va Chai 2009) and/or are prevented from attending meetings due to time poverty. For instance, 'Hmong women wake at $3 \mathrm{am}$ and spend the day working. They have no time to go to class' (Chair, Vietnamese Women's Union (VWU), Lao Va Chai 2009). Some programmes have not factored in cultural taboos adequately in order to ensure equal access to services.

Lastly, Vietnam's limited civil society activity, especially in the case of recent social protection initiatives, has meant that any watchdog function in terms of programme oversight has been weak. While Vietnam's civil society is relatively underdeveloped, this has arguably been exacerbated by the July 2009 'Decree 97', which requires that all local NGOs register with the Prime Minister's office and comply with a list of activities on which NGOs can 'legitimately work'. This list excludes issues related to human rights, gender, minority rights and access to information, with the result that there is limited scope for NGOs to champion greater accountability in resource distribution, social justice and programme implementation. Moreover, even the government-affiliated mass organisation, the VWU, lamented that it lacked information on the NTPPR mid-term evaluation process and did not receive an invitation to be part of the consultation process. While more international NGOs are active on such issues, it is not easy to promote greater civil society activity for the time being.

Source Jones and Tran (2010).

more easily framed as central to social protection objectives.

- Support champions of gender equality - both state and non-state - to forge coalitions with the elite, bureaucratic agency, civil society and donor agencies involved in advancing social protection in order to better integrate context-appropriate understandings of gender dynamics into the design, implementation, monitoring and evaluation of social protection policies and programmes. This could include assisting gender equality advocates to frame gender-specific demands strategically so that they resonate with broader ideas about social protection as well as with institutional mandates and the interests of key actors.

- Advocate for a greater investment in tailored capacity strengthening initiatives within social protection strategies and action plans, in order to address the imbalance in both general and gender-specific capacities among actors engaged in social protection debates.

- Invest in community sensitisation initiatives so that programme participants, as well as non-participants, can better understand and support gender-related social protection programme provisions. 


\section{References}

Bauer, A. and Thant, M. (eds) (2010) Poverty and Sustainable Development in Asia: Impacts and Responses to the Global Economic Crisis, Manila: Asian Development Bank

Centre for Social Protection (CSP) at the Institute of Development Studies (IDS), the Social Protection Programme at the Overseas Development Institute (ODI), the School of International Development at the University of East Anglia (UEA-DEV) and the Regional Hunger \& Vulnerability Programme (RHVP) (2010) Social Protection in Africa: a Way Forward, www.odi.org.uk/resources/download/4884.pdf (accessed 3 August 2011)

Chant, S. (ed.) (2010) The International Handbook of Gender and Poverty: Concepts, Research and Policy, Cheltenham: Edward Elgar

DFID, HelpAge International, Hope \& Homes for Children, Institute of Development Studies, International Labour Organization, Overseas Development Institute, Save the Children UK, UNDP, UNICEF and the World Bank (2009) Advancing Child-Sensitive Social Protection, www.unicef.org/socialpolicy/files/ CSSP_joint_statement_8.20.09.pdf (accessed 3 August 2011)

Hickey, S. (2007) Conceptualising the Politics of Social Protection in Africa, BWPI Working Paper 4, Manchester: Brooks World Poverty Institute Hickey, S. and Bracking, S. (2005) 'Exploring the Politics of Chronic Poverty: From Representation to a Politics of Justice?', World Development 33: 851-65

Holmes, R. and Jones, N. (2010) Social Protection Programming: The Need for a Gender Lens, Briefing
Paper 63, London: Overseas Development Institute

Jones, N. and Holmes, R. (2010) Gender, Politics and Social Protection: Why Social Protection is 'Gender Blind', Briefing Paper 62, London: Overseas Development Institute

Jones, N. and Tran, V.A. (2010) Gendered Risks, Poverty and Vulnerability in Viet Nam. A Case Study of the National Targeted Programme for Poverty Reduction, report to AusAID, London: Overseas Development Institute

Jones, N.; Woldehanna, T. and Tafere, Y. (2010) Gendered Risks, Poverty and Vulnerability in Ethiopia: To What Extent is the Productive Safety Net Programme Making a Difference?, report commissioned by the UK Department for International Development (DFID), London: Overseas Development Institute

Kabeer, N. (2008) Mainstreaming Gender in Social Protection for the Informal Economy, London: Commonwealth Secretariat

McCord, A. (2009) Cash Transfers and Political Economy in Sub-Saharan Africa, Project Briefing Paper 31, London: Overseas Development Institute

Molyneux, M. (2007) Change and Continuity in Social Protection in Latin America: Mothers at the Service of the State?, UNRISD Working Paper, Geneva: United Nations Research Institute for Social Development (UNRISD)

Vargas, R. (2010) Gender Risk, Poverty and Vulnerability in Peru: A Case Study of the Juntos Programme, London: Overseas Development Institute 